\title{
The effect of GaN thickness inserted between two AlN layers on the transport properties of a lattice matched AlInN/AlN/GaN/AlN/GaN double channel heterostructure
}

\author{
R. Tülek ${ }^{\text {a,* }}$, E. Arslan ${ }^{\text {b }}$, A. Bayraklı ${ }^{\text {c }}$, S. Turhan ${ }^{\text {a }}$, S. Gökden ${ }^{\text {a }}$, Ö. Duygulu ${ }^{\text {d }}$, A.A. Kaya ${ }^{\text {e }}$, T. Firat ${ }^{\text {c }}$, \\ A. Teke ${ }^{\text {a }}$ E. Özbay ${ }^{\text {b }}$ \\ a Department of Physics, Faculty of Science and Letters, Bahkesir University, Çağıș Kampüsü, 10145 Balkesir, Turkey \\ ${ }^{\mathrm{b}}$ Department of Physics, Department of Electrical and Electronics Engineering, Nanotechnology Research Center-NANOTAM, Bilkent University, 06800 Ankara, Turkey \\ c Department of Physics Engineering, Faculty of Engineering, Hacettepe University, 06800 Ankara, Turkey \\ d TUBITAK Marmara Research Center, Materials Institute, PO Box 21, Gebze, 41470 Kocaeli, Turkey \\ e Mugla University, Engineering Faculty, Department of Metallurgy and Materials Engineering, 48000 Mugla, Turkey
}

\section{A R T I C L E I N F O}

Article history:

Received 29 March 2013

Received in revised form 29 November 2013

Accepted 29 November 2013

Available online 5 December 2013

\section{Keywords:}

AlInN/GaN single

Double channel

Transport

\begin{abstract}
A B S T R A C T
One AlInN/AlN/GaN single channel heterostructure sample and four AlInN/AlN/GaN/AlN/GaN double channel heterostructure samples with different values of the second GaN layer were studied. The interface profiles, crystalline qualities, surface morphologies, and dislocation densities of the samples were investigated using high resolution transmission electron microscopy, atomic force microscopy, and high-resolution X-ray diffraction. Some of the data provided by these measurements were used as input parameters in the calculation of the scattering mechanisms that govern the transport properties of the studied samples. Experimental transport data were obtained using temperature dependent Hall effect measurements (10-300 K) at low (0.5 T) and high $(8 \mathrm{~T})$ magnetic fields to exclude the bulk transport from the two-dimensional one. The effect of the thickness of the second GaN layer inserted between two AlN barrier layers on mobility and carrier concentrations was analyzed and the dominant scattering mechanisms in the low and high temperature regimes were determined. It was found that Hall mobility increases as the thickness of GaN increases until $5 \mathrm{~nm}$ at a low temperature where interface roughness scattering is observed as one of the dominant scattering mechanisms. When GaN thicknesses exceed $5 \mathrm{~nm}$, Hall mobility tends to decrease again due to the population of the second channel in which the interface becomes worse compared to the other one. From these analyses, $5 \mathrm{~nm}$ GaN layer thicknesses were found to be the optimum thicknesses required for high electron mobility.
\end{abstract}

(C) 2013 Published by Elsevier B.V

\section{Introduction}

GaN-based high electron mobility transistors (HEMTs) have attracted great interest for high power and high frequency electronic devices because nitride based material systems have fundamental physical properties, such as a large band gap, large breakdown field, and strong spontaneous and piezoelectric polarization fields [1]. Many studies have been performed to improve the performance of devices, such as increasing the $\mathrm{Al}$ composition of an AlGaN barrier [2], using a thin AlN spacer layer at the AlGaN/GaN interface $[3,4]$, and replacing the GaN with InGaN as the channel [5,6] and AlGaN with AlInN [7-16] as the barrier. Among these, the lattice-matched AlInN barrier is considered to be the most promising barrier alternative for improving the HEMT performance. In lattice matched AlInN/GaN HEMTs, the polarization charge is completely determined by spontaneous polarization since the structure is free of strain. HEMTs with nearly lattice matched AlInN barrier layers

\footnotetext{
* Corresponding author.
}

were essentially predicted to provide higher carrier densities than in those with an AlGaN barrier layer [8], which is promising for high power and high frequency transistor operations [14]. Gonschorek et al. [10] reported a high density of carriers $\left(2.6 \times 10^{13} \mathrm{~cm}^{-2}\right)$ with the electron mobility of $1170 \mathrm{~cm}^{2} /$ Vs resulting in a low sheet resistance of $210 \Omega / \mathrm{sq}$ at room temperature (RT) for an AlInN/GaN heterostructure. Similarly, Tulek et al. [14] reported a very high electron density of $4.23 \times 10^{13} \mathrm{~cm}^{-2}$ with a corresponding electron mobility of $812 \mathrm{~cm}^{2} / \mathrm{Vs}$ which yielded a record two-dimensional sheet resistance of $182 \Omega / s q$ for heterostructure with an $\mathrm{Al}_{0.88} \mathrm{In}_{0.12} \mathrm{~N}$ barrier layer. In addition, the introduction of a thin AlN spacer layer at the AlInN/GaN interface increases the carrier density and effectively reduces the alloy scattering of two-dimensional electron gas (2DEG) as well as provides better carrier confinement $[14,15]$.

Another alternative approach in designing the structure of the GaN based HEMTs is the use of double channels. This is achieved by inserting an AlN/GaN/AlN interlayer between a GaN channel and an AlInN barrier. A second channel is formed at the AlN/GaN interface of the extra inserting layer. 
The occupation of the second channel depends on the thickness of the GaN layer, which will be discussed later. Recently, some studies have appeared in the literature. Zhang et al. [17,18] reported a double channel (DC) AlInN/GaN heterostructure with high electron mobility and low sheet resistance compared to a single channel (SC). They reported higher RT electron mobility $\left(1570 \mathrm{~cm}^{2} / \mathrm{Vs}\right)$ along with lower sheet resistance (222 $\Omega / \mathrm{sq}$ ) in AlInN/GaN DC compared to an AlInN/ GaN SC heterostructure [17]. The same group [18] investigated the effect of distance between dual channel $\left(d_{1}\right)$ and the thickness of the bottom AlN insert layer $\left(d_{2}\right)$ on the transport properties of AlInN/GaN DC HEMTs. In this study, for $\mathrm{d}_{1} / \mathrm{d}_{2}(7 / 1.5)$, the lowest sheet resistance of $231.8 \Omega /$ sq along with an electron mobility of $1580 \mathrm{~cm}^{2} /$ Vs was reported. Additionally, in our previous work [15] we have investigated a group of AllnN/GaN/AlN/GaN heterostructures some of which include a thin (2-3 nm) unintentional GaN layer on top of the AIN spacer due to residual Ga in the chamber during growth. It was found that the sample including the unintentional GaN (is now considered as a second channel if populated by carriers) with a $1 \mathrm{~nm}$ AlN spacer layer showed better transport performance.

In the present work, we investigated the transport properties of AlInN/AlN/GaN/AlN/GaN double heterostructures depending on the thickness of the GaN layers inserted between two AlN layers using temperature dependent Hall effect measurements (10-300 K) at low $(0.5 \mathrm{~T})$ and high $(8 \mathrm{~T})$ magnetic fields. The thicknesses of this layer were chosen as 2, 3, 5, and $7 \mathrm{~nm}$. An AlInN/AlN/GaN single channel heterostructure was used as reference. Hall data were first analyzed to extract the temperature dependent mobilities and carrier densities of the bulk and two dimensional (2D) channels using a simple parallel conduction extraction method (SPCEM) [19]. Then, the potential profiles of conduction and valance bands and spatial distribution of the amplitude of the electron wave functions were calculated by solving a 1D nonlinear self-consistent Schrödinger-Poisson equation [20]. This would allow us to determine whether the second channel is populated or not. By taking these results into account, two dimensional electron gasses were analyzed using the main scattering mechanisms that govern the transport properties of devices in the temperature range of 10-300 K.

\section{Experimental details}

The $\mathrm{Al}_{1}-{ }_{\mathrm{x}} \mathrm{In}_{\mathrm{x}} \mathrm{N} / \mathrm{AlN} / \mathrm{GaN}(\mathrm{x} \cong 0.17) \mathrm{SC}$ and $\mathrm{Al}_{1}-{ }_{\mathrm{x}} \operatorname{In}_{\mathrm{x}} \mathrm{N} / \mathrm{AlN} / \mathrm{GaN} /$ AlN/GaN ( $\cong 00.17)$ DC heterostructures were grown on doublepolished 2-in diameter $\mathrm{c}$-face $\mathrm{Al}_{2} \mathrm{O}_{3}$ substrates in a low pressure metal organic chemical vapor deposition reactor (Aixtron 200/4 HT-S) by using trimethylgallium, trimethylaluminum, trimethylindium, and ammonia as $\mathrm{Ga}$, $\mathrm{Al}$, In, and $\mathrm{N}$ precursors, respectively. Prior to the epitaxial growth, $\mathrm{Al}_{2} \mathrm{O}_{3}$ substrate was annealed at $1100{ }^{\circ} \mathrm{C}$ for $10 \mathrm{~min}$ in order to remove surface contamination. The buffer structures consisted of a $15 \mathrm{~nm}$ thick, low-temperature $\left(770{ }^{\circ} \mathrm{C}\right)$ AlN nucleation layer, and high temperature $\left(1120^{\circ} \mathrm{C}\right) 270 \mathrm{~nm}$ AlN templates. A $1.16 \mu \mathrm{m}$ nominally undoped GaN layer was grown on an AlN template layer at $1060{ }^{\circ} \mathrm{C}$, followed by a $1.5 \mathrm{~nm}$ thick high temperature AlN barrier layer $\left(1075^{\circ} \mathrm{C}\right)$. The AlN barrier layer was used to reduce the alloy disorder scattering by minimizing the wave function penetration from the two-dimensional electron gas (2DEG) channel into the AlInN layer. After the deposition of these layers, a $7 \mathrm{~nm}$ thick undoped $\mathrm{Al}_{0.83} \mathrm{In}_{0.17} \mathrm{~N}$ barrier layer was grown at $830{ }^{\circ} \mathrm{C}$. Finally, a $1.2-\mathrm{nm}$-thick GaN cap layer growth was carried out at a temperature of $830{ }^{\circ} \mathrm{C}$. The double channel heterostructures, from the GaN buffer, consist of $1.5 \mathrm{~nm}$ AlN layer $\left(1075^{\circ} \mathrm{C}\right)$, GaN channel layer $\left(1075^{\circ} \mathrm{C}\right)$ and $1 \mathrm{~nm}$ AlN layer, and continued with the $13 \mathrm{~nm} \mathrm{Al}{ }_{0.83} \mathrm{In}_{0.17} \mathrm{~N}$ barrier layer. In four DC samples, different GaN thicknesses were grown. The samples with $0,2,3,5$, and $7 \mathrm{~nm}$ GaN layer thicknesses will be referred to as $\mathrm{A}, \mathrm{B}, \mathrm{C}, \mathrm{D}$, and $\mathrm{E}$, respectively. The thickness of the $\mathrm{Al}_{0.83} \mathrm{In}_{0.17} \mathrm{~N}$ barrier layer in the DC heterostructures is grown at $830{ }^{\circ} \mathrm{C}$. Finally, a $2 \mathrm{~nm}$
GaN nm-thick GaN cap layer growth was carried out at a temperature of $830{ }^{\circ} \mathrm{C}$ in DC heterostructures.

Prior to ohmic contact formation, the samples were cleaned. The samples are cleaned with acetone in an ultrasonic bath. Then, a sample was treated with boiling isopropyl alcohol for $5 \mathrm{~min}$ and rinsed in de-ionized (DI) water having a $18 \mathrm{M} \Omega$ resistivity. Then, the samples were dipped in a solution of $\mathrm{HCl} / \mathrm{H}_{2} \mathrm{O}(1: 2)$ for $30 \mathrm{~s}$ in order to remove the surface oxides, and then rinsed in DI water again for a prolonged period. After cleaning, the ohmic contacts were formed as a square van der Pauw shape by using electron beam evaporation at approx. $1.33 \times 10^{-5} \mathrm{~Pa}$. The Ti/Al/Ni/Au (17/170/50/80 nm) metals were thermally evaporated on the sample and were annealed at $850{ }^{\circ} \mathrm{C}$ for $30 \mathrm{~s}$ in $\mathrm{N}_{2}$ ambient in order to form the ohmic contact.

The crystalline quality and dislocation densities of the GaN layers and the $\mathrm{Al}$ and In compositions of the barrier layers were examined by using a Rigaku SmartLab high-resolution diffractometer system (HR-XRD), delivering a $\mathrm{CuK}_{\alpha 1}(1.54 \AA \AA$ ) radiation, using a prodded mirror, 4-bounce $\mathrm{Ge}$ (220) symmetric monochromator.

The interface profile and crystalline quality of the SC and DC heterostructures were investigated by high resolution transmission electron microscopy (HRTEM). The specimens were examined by using a JEOL 2100 high resolution transmission electron microscope ( $\mathrm{LaB}_{6}$ filament) operated at $200 \mathrm{kV}$. The surface morphology of the samples was studied by atomic force microscopy (AFM).

The Hall mobility and carrier density versus temperature measurements were performed with van der Pauw and Hall techniques at a temperature range of 10-300 K by using the Quantum Design physical property measurement system.

\section{Experimental results}

The structural quality and the alloy compositions of the SC and DC heterostructures samples were determined by HR-XRD measurements. Fig. 1 shows $\omega-2 \theta$ scan XRD patterns around the (002) reflection for SC and DC heterostructures. Three diffraction peaks were observed from the AlN, GaN, and $\operatorname{In}_{\mathrm{x}} \mathrm{Al}_{1}{ }_{-} \mathrm{N}$ layers. The well-resolved diffraction peaks related to AlInN barrier layers are observed at around $35.3^{\circ}$. Assuming Vegard's law to be valid, the In molar fraction $\mathrm{x}$ was calculated from the $\mathrm{Al}_{1}{ }_{-} \mathrm{In}_{\mathrm{x}} \mathrm{N}$ ternary layer separation. The In molar fraction $\mathrm{x}$ of $\mathrm{Al}_{1}-{ }_{\mathrm{x}} \mathrm{In}_{\mathrm{x}} \mathrm{N}$ alloy in all the samples was $\mathrm{x} \sim 0.17$.

The defects within the structure of the sample cause significant broadening in both the symmetric (002) and asymmetric (102) rocking curves. The XRD symmetric (002) incorporated with asymmetric (102) scan is a reliable technique to characterize the crystal quality of GaN

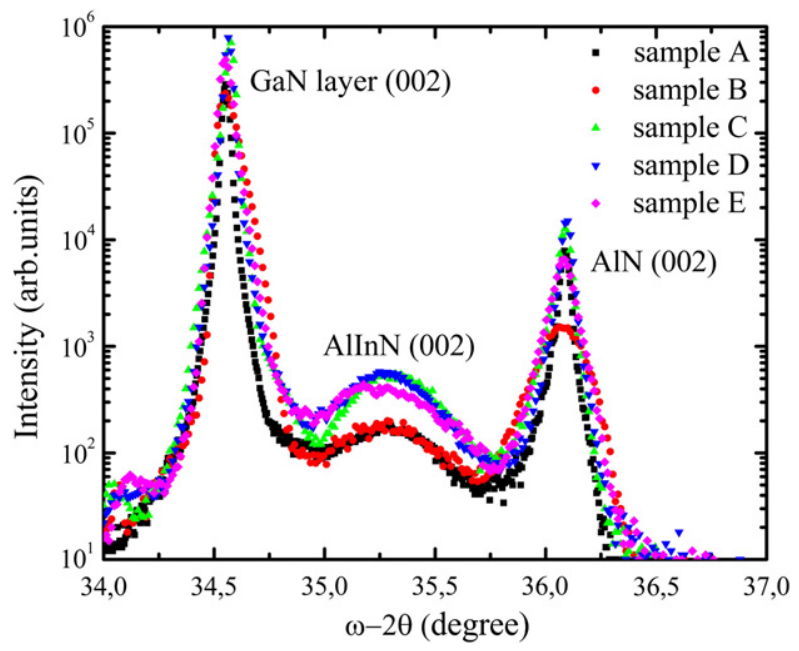

Fig. 1. HR-XRD (002) $\omega-2 \theta$ scans of $\mathrm{Al}_{83} \mathrm{In}_{17} \mathrm{~N} / \mathrm{AIN} / \mathrm{GaN} \mathrm{SC}$ (sample $\mathrm{A}$ ) and $\mathrm{Al}_{0.83} \mathrm{In}_{0.17} \mathrm{~N} /$ AIN/GaN/AlN/GaN DC heterostructures with increasing GaN layer thickness (samples B to $\mathrm{E})$. 
films. The dislocation density in the structures can be calculated by using a mosaic model. The details of the calculation method of the dislocation density use can be found in Ref. [21]. The edge and screw type of the dislocation densities calculated for SC and DC heterostructures are given in Table 1 . The edge and screw type of the dislocation densities were calculated as $3.6 \times 10^{8} \mathrm{~cm}^{-2}$ and $4.9 \times 10^{7} \mathrm{~cm}^{-2}$ in the GaN templates for the SC heterostructures, respectively. In the DC heterostructures, the edge type of the dislocation densities changes between $1.8 \times 10^{8} \mathrm{~cm}^{-2}$ and $2.4 \times 10^{8} \mathrm{~cm}^{-8}$ and screw type of the dislocation between $1 \times 10^{7} \mathrm{~cm}^{-2}$ and $3.4 \times 10^{7} \mathrm{~cm}^{-2}$, respectively.

Typical AFM images of SC (sample A) and DC (sample C and sample E) are presented in Fig. 2. The root-mean-square (rms) surface roughness values obtained from the AFM scans of the all the samples were summarized in Table 1. As can be seen from Fig. 2a, the SC sample shows a rough surface morphology with an rms value of $0.29 \mathrm{~nm}$. For DC heterostructures samples, the rms surface roughness changes between 0.33 and $0.41 \mathrm{~nm}$, and there is no systematical behavior as a function of GaN thickness.

The interface profile and the layer thickness of the SC and DC heterostructures were investigated by transmission electron microscopy (TEM). Fig. 3 shows the cross-section TEM image of the AlInN/ AlN/GaN SC heterostructure and $\mathrm{Al}_{0.83} \mathrm{In}_{0.17} \mathrm{~N} / \mathrm{AlN} / \mathrm{GaN} / \mathrm{AlN} / \mathrm{GaN} \mathrm{DC}$ heterostructures. The image (Fig. 3a) shows that the SC heterostructure is composed of $7 \mathrm{~nm}$ AlInN barrier, $1.5 \mathrm{~nm}$ AlN layer, and $1.2 \mathrm{~nm} \mathrm{GaN}$ cap layer. The DC heterostructure (in Fig. 3b and c) is composed of a $13 \mathrm{~nm}$ AlInN barrier layer, two AlN interlayers (top: $1 \mathrm{~nm}$ and bottom: $1.5 \mathrm{~nm}$ ), and GaN channels with distances of approx. 3 and $7 \mathrm{~nm}$ in samples $\mathrm{C}$ and $\mathrm{E}$, respectively.

Temperature-dependent Hall measurements were carried out from 10 to $300 \mathrm{~K}$ using van der Pauw geometry. Fig. 4 shows the temperature dependent Hall sheet carrier density at 0.5 T magnetic fields for all the samples. As seen in Fig. 4, sheet carrier densities increase as the temperature increases for all samples. Because the 2DEG carrier density is expected to become temperature independent [22], this dependence is attributed to the thermal activation of bulk carriers. Therefore, the observed total carrier densities are due to both the bulk and 2DEG types. Although the total carrier density decreases as the thicknesses of the GaN layer increase at low temperature they do not show the same behavior at temperatures higher than $200 \mathrm{~K}$ due to the enhancement of the thermal activation of bulk carriers in the second channel. To separate the origin of this carrier type, SPCEM analyses were carried out using low and high magnetic field Hall data for samples A, D, and E. In the application of SPCEM analysis, some assumptions are made. (i) At low temperatures, bulk carriers are assumed to be frozen. Therefore, the measured Hall carrier density at the lowest temperature is the 2DEG type that remains constant in the whole range of temperatures. (ii) The temperature dependence of the measured carrier density is associated with bulk carriers only. The carrier density and the mobility of 2DEG and bulk carriers were calculated separately with these assumptions. The details of calculations are given in Ref. [23].

To determine whether the second channel is populated the potential profiles of conduction and valance bands and spatial distribution of the amplitude of electron wave functions were calculated by solving 1D nonlinear self-consistent Schrödinger-Poisson equation. Fig. 5 shows
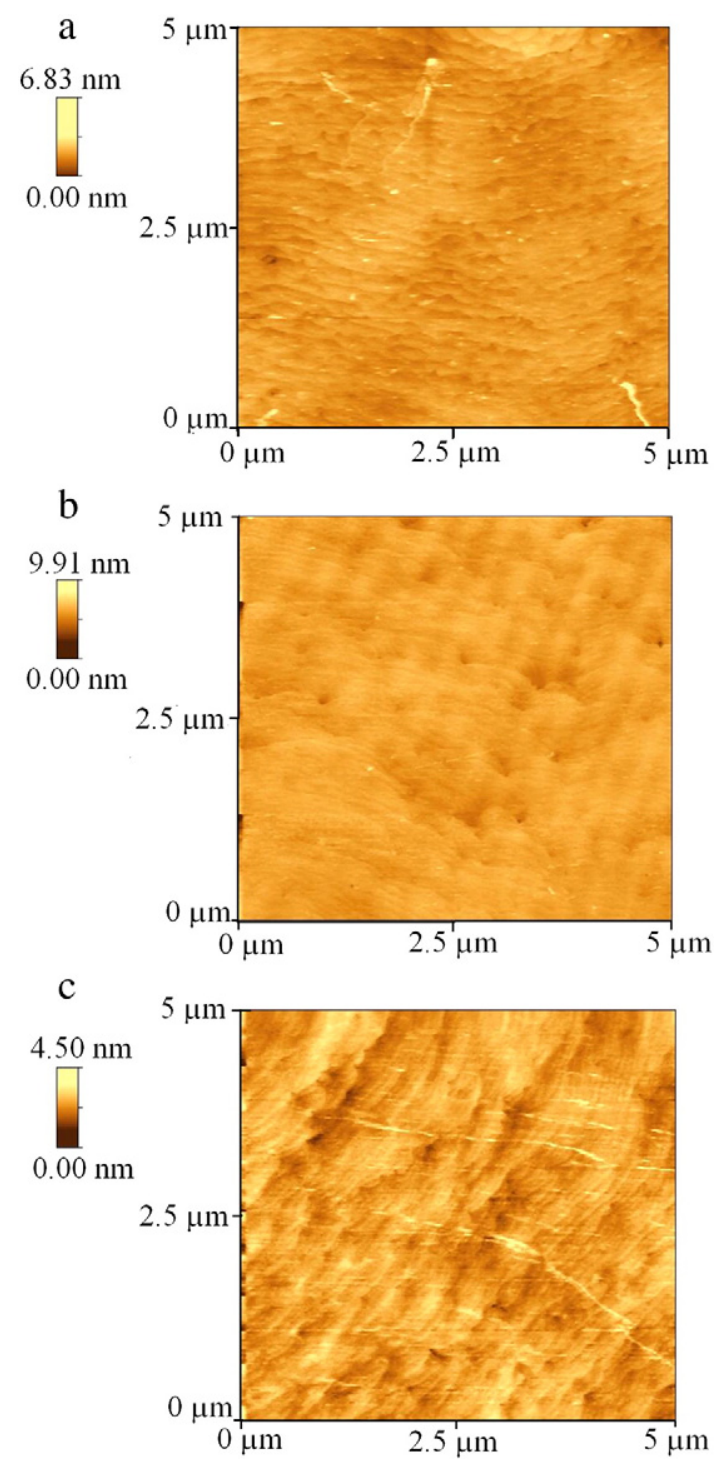

Fig. 2. The AFM images ( $5 \mu \mathrm{m} \times 5 \mu \mathrm{m}$ ) of (a) sample A (SC heterostructures), (b) sample $C$ (DC heterostructures) and (c) sample E, with 3 and $7 \mathrm{~nm}$ GaN layer thicknesses, respectively. The rms surface roughnesses are $0.29,0.33$, and $0.36 \mathrm{~nm}$ for sample A, sample $\mathrm{C}$, and sample E, respectively.

conduction band profiles and spatial distribution electron wave functions for all samples. As seen in the figure, the second channels are not populated for samples B, C, and D. On the other hand, as seen in the same figure the second channel is populated only for sample $\mathrm{E}$.

Here, we will discuss the temperature-dependent Hall mobility's for all the samples along with the results of the theoretical model to investigate the transport properties. The model accounts for the major scattering mechanisms such as optical phonon and acoustic phonon, through deformation potential and piezoelectric, background impurity,

Table 1

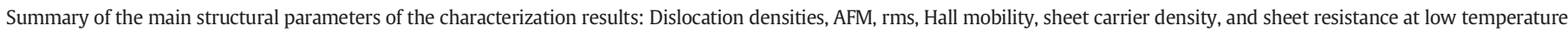
and RT.

\begin{tabular}{|c|c|c|c|c|c|c|c|c|c|}
\hline \multirow[t]{2}{*}{ Sample. } & \multicolumn{2}{|c|}{$\begin{array}{l}\text { Dislocation densities } \\
\left(\times 10^{8} \mathrm{~cm}^{-2}\right)\end{array}$} & \multirow[t]{2}{*}{$\begin{array}{l}\mathrm{rms} \\
(\mathrm{nm})\end{array}$} & \multicolumn{2}{|c|}{$\begin{array}{l}\text { Mobility } \\
\left(\mathrm{cm}^{2} / \mathrm{Vs}\right) \pm 2\end{array}$} & \multicolumn{2}{|c|}{$\begin{array}{l}\text { Sheet carrier density } \\
\left( \pm 0.01 \times 10^{13} \mathrm{~cm}^{-2}\right)\end{array}$} & \multicolumn{2}{|c|}{$\begin{array}{l}\text { Sheet resistance } \\
(\Omega / \mathrm{sq}) \pm 0.02\end{array}$} \\
\hline & Edge & Screw & & $10 \mathrm{~K}$ & $300 \mathrm{~K}$ & $10 \mathrm{~K}$ & $300 \mathrm{~K}$ & $10 \mathrm{~K}$ & $300 \mathrm{~K}$ \\
\hline A & $3.6 \pm 0.1$ & $0.5 \pm 0.2$ & 0.29 & 4133 & 1000 & 2.22 & 2.79 & 68.08 & 224.16 \\
\hline B & $1.8 \pm 0.3$ & $0.3 \pm 0.2$ & 0.34 & 6106 & 1143 & 1.83 & 2.21 & 55.98 & 246.72 \\
\hline$C$ & $2.4 \pm 0.1$ & $0.1 \pm 0.1$ & 0.33 & 14,971 & 1329 & 1.16 & 2.04 & 36.21 & 230.94 \\
\hline D & $2.3 \pm 0.2$ & $0.1 \pm 0.3$ & 0.41 & 26,763 & 1108 & 0.88 & 2.37 & 26.45 & 237.52 \\
\hline $\mathrm{E}$ & $2.1 \pm 0.2$ & $0.17 \pm 0.2$ & 0.36 & 24,055 & 985 & 0.70 & 2.55 & 37.15 & 248.82 \\
\hline
\end{tabular}



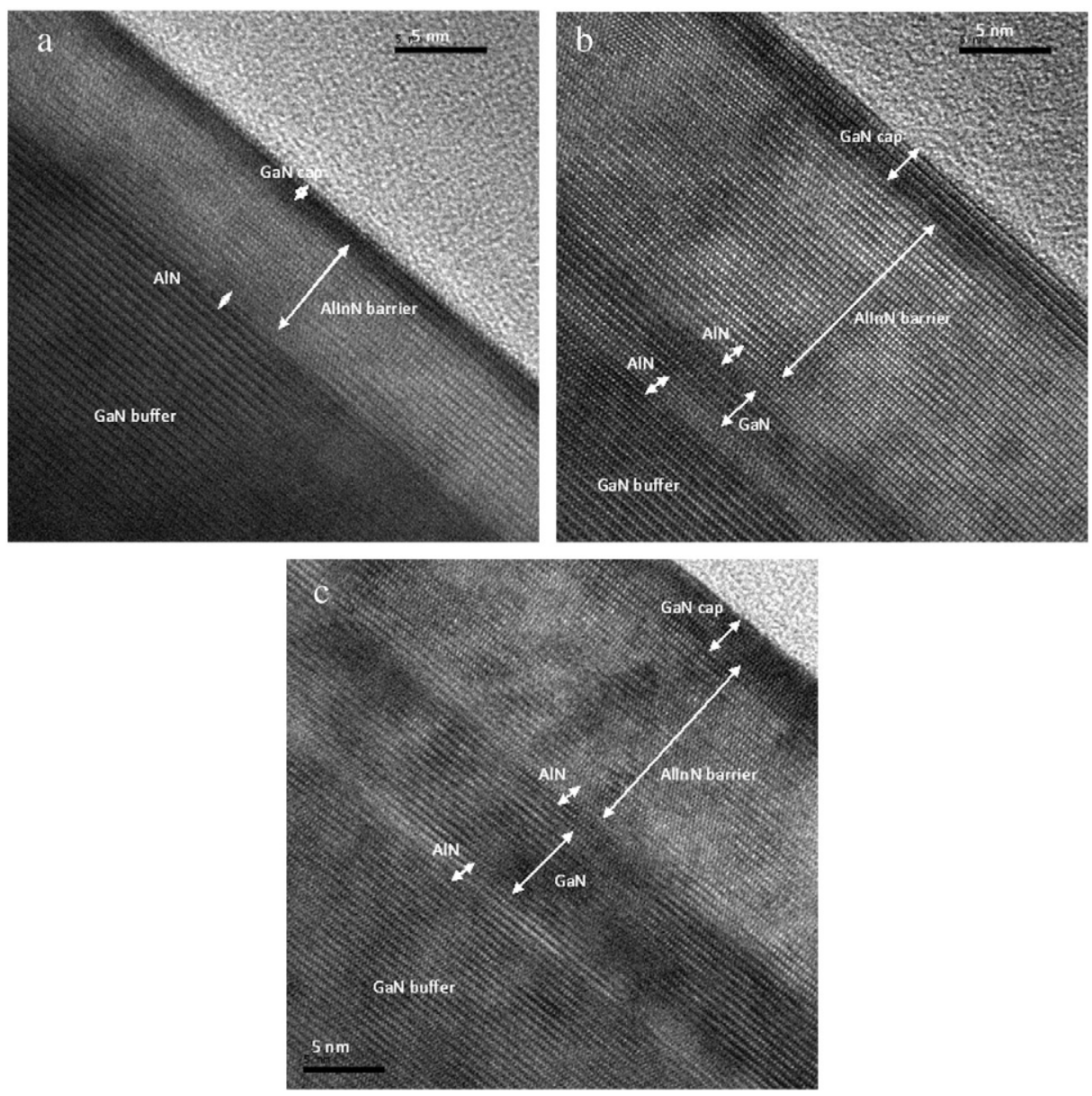

Fig. 3. The cross-section TEM image of the (a) AlInN/AIN/GaN SC and AllnN/AlN/GaN/AlN/GaN DC heterostructures with (b) $5 \mathrm{~nm}$ GaN and (c) $7 \mathrm{~nm}$ GaN layers.

interface roughness, alloy disorder and dislocation scatterings. The details of the calculations are given in Ref. [24] and references therein. The parameters used in these calculations are taken from Ref. [1] and tabulated in Table 2. The results are given in Fig. 6. The calculated total mobility as a function of lattice temperature is in very good agreement with the experimental data for all the samples. The temperaturedependent Hall mobility revealed that the Hall mobilities in samples A (Fig. 6a) and B (Fig. 6b) are determined by interface roughness scattering at low temperatures. As the temperature increases, acoustic phonon scattering in addition to the interface roughness becomes operative in

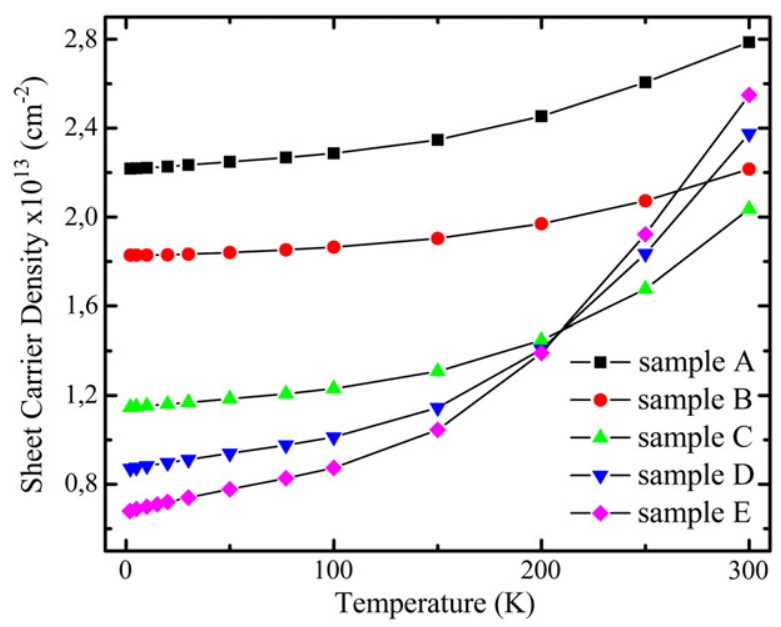

Fig. 4. The temperature dependence of measured sheet carrier density for all samples. the determination of overall mobilities. At higher temperatures, the mobilities are limited by a combination of optical phonon, interface roughness, and acoustic phonon scattering mechanisms. Mobilities for samples C (Fig. 6c), D (Fig. 6d), and E (Fig. 6e) are limited by the interface roughness and acoustic phonon scattering at low temperature and acoustic phonon scattering at moderate temperature ranges. Above $200 \mathrm{~K}$, acoustic and optical phonon scattering become effective in the determination of the mobility. The strength of the optical phonon component increases as the temperature reaches RT.

Let us now discuss the effect of the GaN layer on the transport characteristics of our AlInN/AlN/GaN/AIN/GaN HEMT structure in detail. Fig. 7 shows Hall mobility and as a function of GaN thicknesses for all samples at $10 \mathrm{~K}$. As seen, Hall mobility increases as GaN thickness increases until $5 \mathrm{~nm}$ at low temperature. When GaN thicknesses exceed $5 \mathrm{~nm}$, Hall mobility decreases again. Interface roughness scattering (IFR) is one of the dominant scattering mechanisms in our samples at low temperature. In general, there are two parameters used in the calculation of the mobility limited purely by interface roughness scattering, namely the correlation length $\Lambda$ and the lateral size $\Delta$ at the AlN/GaN interface, respectively. In the calculation, the rms roughness values obtained from AFM scans were taken as the lateral size parameter $(\Delta)$. The correlation length was taken in the range of 5-25 $\mathrm{nm}$ [25] as a free parameter to fit the experimental mobility data. The mobility increases as $\Delta$ decreases and $\Lambda$ increases and hence the larger the $\Lambda / \Delta$, the smoother the interface. Therefore, we plotted lambda/delta $(\Lambda / \Delta)$ as a function of GaN thickness, which is shown in Fig. 7. In this calculation, the effect of sheet carrier density on the shift of the centroid of the electron distribution toward the interface that promotes the effectiveness of the interface roughness scattering [26] was also taken into account. The larger the $\Lambda / \Delta$, the smoother the interface becomes. As 

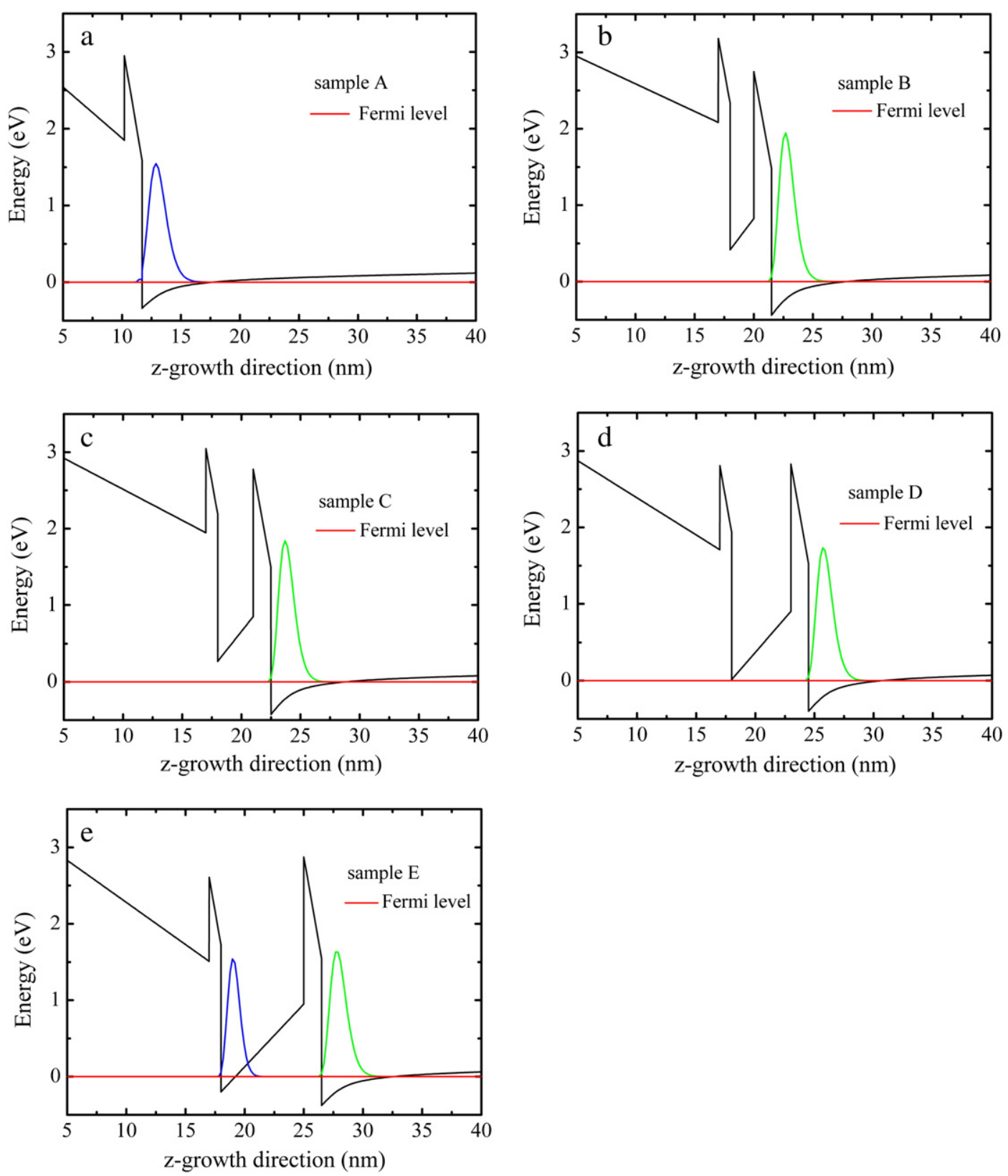

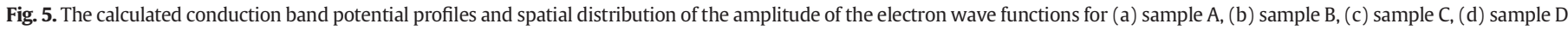
and (e) sample E.

seen in the figure, the $\Lambda / \Delta$ increases as the GaN thickness increases up to $5 \mathrm{~nm}$, and then it decreases again as the GaN thickness increases further. The mobility follows the same behavior that can be interpreted

Table 2

Values of GaN material constants used in the calculation of scattering mechanisms.

\begin{tabular}{ll} 
Electron effective mass $\left(\mathrm{m}_{0}\right)$ & $\mathrm{m}^{*}=0.22$ \\
High frequency dielectric constant $\left(\varepsilon_{0}\right)$ & $\varepsilon_{\infty}=5.35$ \\
Static dielectric constant $\left(\varepsilon_{0}\right)$ & $\varepsilon_{\mathrm{s}}=8.9$ \\
LO-phonon energy $(\mathrm{meV})$ & $\hbar \omega=92$ \\
Longitudinal acoustic phonon velocity $(\mathrm{m} / \mathrm{s})$ & $\mathrm{v}_{\mathrm{L}}=6.56 \times 10^{3}$ \\
Density of the crystal $\left(\mathrm{kg} / \mathrm{m}^{3}\right)$ & $\rho=6.15 \times 10^{3}$ \\
Deformation potential $(\mathrm{eV})$ & $\mathrm{E}_{\mathrm{D}}=8.3$ \\
The electromechanical coupling coefficient & $\mathrm{K}^{2}=0.039$ \\
Electron wave vector $\left(\mathrm{m}^{-1}\right)$ & $\mathrm{k}=7.27 \times 10^{8}$ \\
Effective Bohr radius in the material $(\AA)$ & $\mathrm{a}_{\mathrm{B}}=23.1$ \\
Lattice constant in the $(0001)$ direction $(\AA)$ & $\mathrm{c}_{0}=5.185$ \\
The 2D Thomas Fermi wave vector $\left(\mathrm{m}^{-1}\right)$ & $\mathrm{q}_{\mathrm{TF}}=8.68 \times 10^{8}$ \\
\hline
\end{tabular}

as follows. As seen from the calculation of the potential profile, only the first channel is populated for the samples A, B, C, and D with the thicknesses of the second channel at $0,2,3$, and $5 \mathrm{~nm}$, respectively. The mobility gradually increases when the thickness of the GaN layer in the second channel increases up to $5 \mathrm{~nm}$ due to an increase in the $\Lambda / \Delta$ ratio. This indicates that the AlN/GaN interface becomes smoother. When the GaN thickness in the second channel is set to $7 \mathrm{~nm}$, the second channel is populated slightly. Once the second channel becomes populated, there will be two interfaces (AlN/GaN and GaN/AlN) in this channel. It is well known that the inverted interface ( $\mathrm{GaN}$ on $\mathrm{AlN})$ is worsened compared to the normal interface (AIN on GaN). Since only the $16 \%$ of the total sheet carrier density is in the second channel the effect of the rough interface in this channel on Hall mobility is not adverse. However, above $5 \mathrm{~nm}$ the carrier population in the second channel becomes comparable to that in the first channel, and hence the overall interface worsens as seen in the figure where the $\Lambda / \Delta$ ratio decreases. Its effect on Hall mobility is clearly observed as a decrease in the figure. 

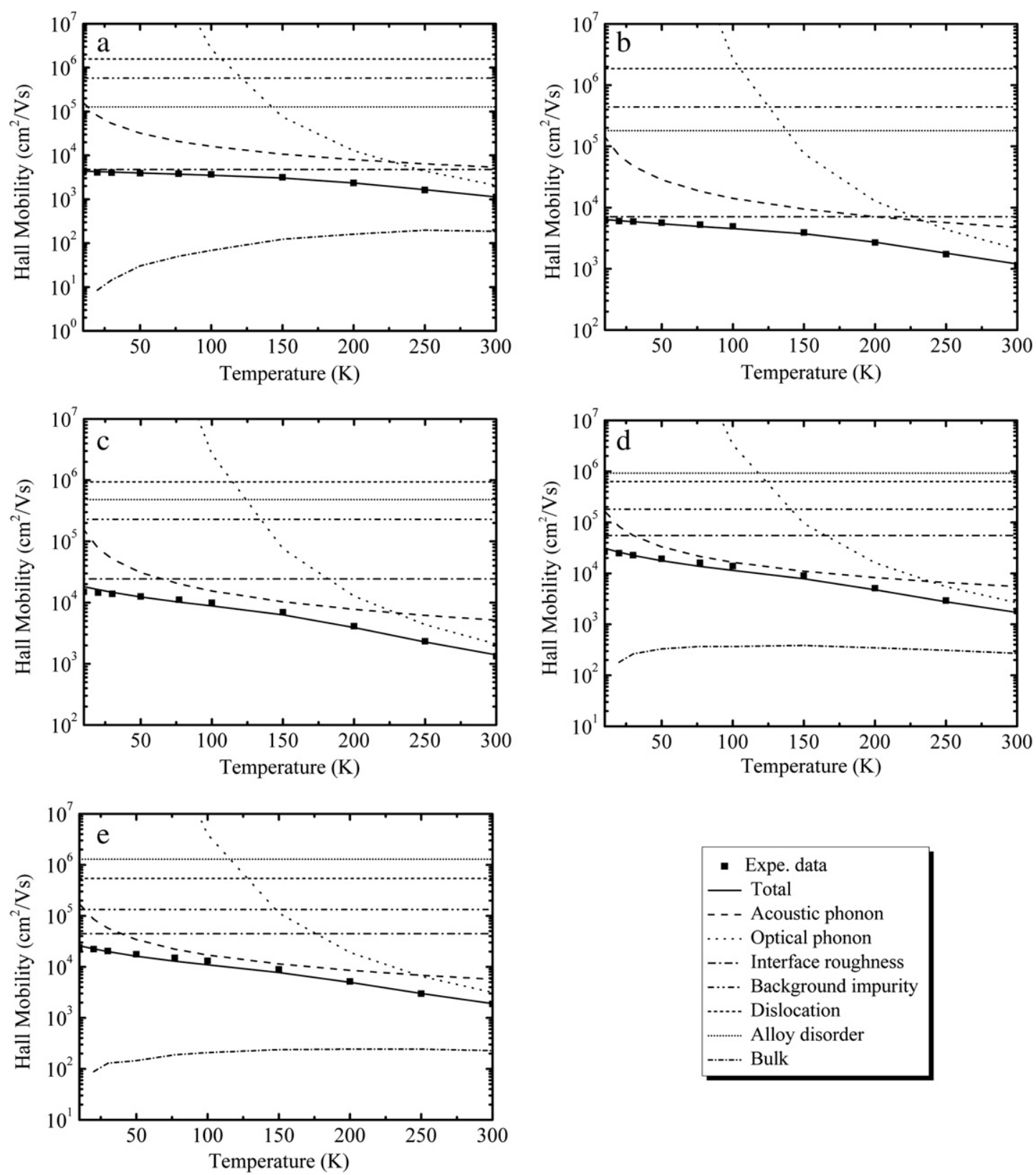

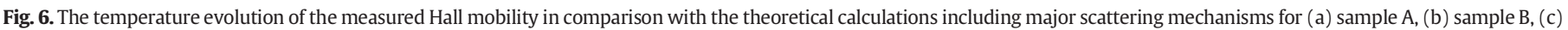
sample C, (d) sample D and (d) sample E (legend box is for all graphs).

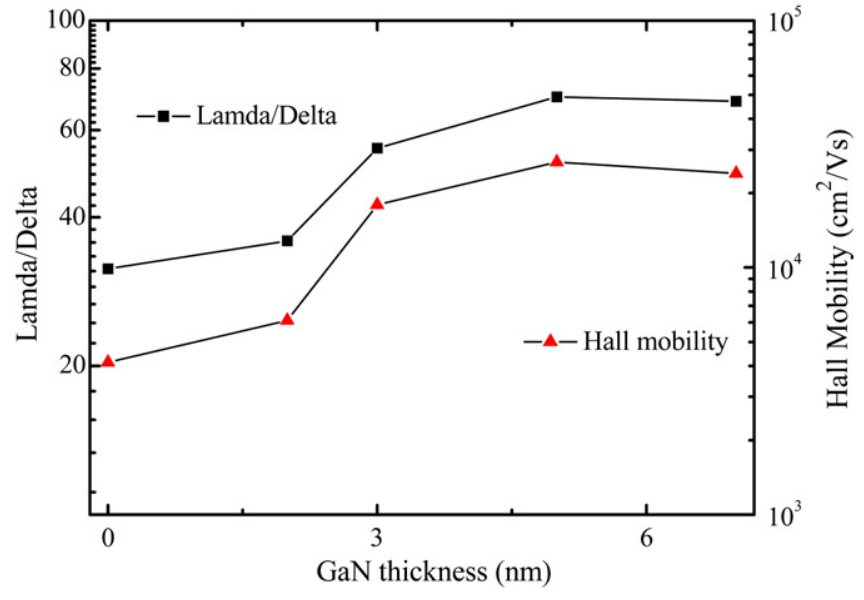

Fig. 7. $\Lambda / \Delta$ and low-temperature Hall mobility as a function of GaN thicknesses.

\section{Conclusions}

We studied the transport properties of AlInN/AlN/GaN/AlN/GaN DC heterostructures with various second GaN layer thicknesses by using temperature dependent Hall measurements and compared them to AlInN/AlN/GaN SC. The effect of thickness of the second GaN layer inserted between two AlN barrier layers on mobility and carrier concentrations was analyzed and the dominant scattering mechanisms in the low and high temperature regimes were determined. It was found that Hall mobility increases as the thickness of GaN increases until $5 \mathrm{~nm}$ at low temperature where IFR scattering is observed as one of the dominant scattering mechanisms. When GaN thicknesses exceed $5 \mathrm{~nm}$, Hall mobility tends to decrease again due to the population of the second channel in which the interface worsens compared to the first one. From these analyses, $5 \mathrm{~nm}$ GaN layer thicknesses were found to be the optimum thicknesses required for high electron mobility. This work has emphasized that the AlInN/AIN/GaN/AIN/GaN DC HEMT 
structure after further optimization of the growth and design parameters could show better transport performance compared to AlInN/AlN/ GaN SC based HEMTs.

\section{References}

[1] H. Morkoç, Handbook of Nitride Semiconductors and Devices, vols. I-III, Wiley-VCH, New York, 2008.

[2] Y.-F. Wu, B.P. Keller, P. Fini, S. Keller, T.J. Jenkins, L.T. Kehias, S.P. Denbaars, U.K. Mishra, IEEE Electron. Device Lett. 19 (1998) 50.

[3] I.P. Smorchkova, L. Chen, T. Mates, L. Shen, S. Heikman, B. Moran, S. Keller, S.P. Den Baars, J.S. Speck, U.K. Mishra, J. Appl. Phys. 90 (2001) 3998.

[4] Y. Cao, D. Jena, Appl. Phys. Lett. 90 (2007) 182112

[5] G. Simin, X.H. Hu, A. Taraku, J.P. Zhang, A. Koudymov, S. Saygi, J.W. Yang, A. Khan, M.S. Shur, R. Gaska, Jpn. J. Appl. Phys. 40 (2001) L1142.

[6] S. Gökden, R. Tülek, A. Teke, J.H. Leach, Q. Fan, J. Xie, Ü. Özgür, H. Morkoç, S.B. Lisesivdin, E. Özbay, Semicond. Sci. Technol. 25 (2010) 045024.

[7] J. Kuzmík, IEEE Trans. Electron. Dev. 22 (2001) 510.

[8] J. Kuzmík, Semicond. Sci. Technol. 17 (2002) 540.

[9] A. Dadgar, F. Schulze, J. Bläsing, A. Diez, A. Krost, M. Neuburger, E. Kohn, I. Daumiller, M. Kunze, Appl. Phys. Lett. 85 (2004) 5400.

[10] M. Gonschorek, J.-F. Carlin, E. Feltin, M.A. Py, N. Grandjean, Appl. Phys. Lett. 89 (2006) 062106.

[11] J. Xie, X. Ni, M. Wu, J.H. Leach, Ü. Özgür, H. Morkoç, Appl. Phys. Lett. 91 (2007) 132116

[12] R. Butté, J.-F. Carlin, E. Feltin, M. Gonschorek, S. Nicolay, G. Christmann, D. Simeonov, A. Castiglia, J. Dorsaz, H.J. Buehlmann, S. Christopoulos, G. Baldassarri Höger von
Högersthal, A.J.D. Grundy, M. Mosca, C. Pinquier, M.A. Py, F. Demangeot, J. Frandon, P.G. Lagoudakis, J.J. Baumberg, N. Grandjean, J. Phys. D 40 (2007) 6328.

[13] K. Jeganathan, M. Shimizu, H. Okumura, Y. Yano, N. Akutsu, J. Cryst. Growth 304 (2007) 342.

[14] R. Tulek, A. Ilgaz, S. Gokden, A. Teke, M.K. Ozturk, M. Kasap, S. Ozcelik, E. Arslan, E. Ozbay, J. Appl. Phys. 105 (2009) 013707.

[15] A. Teke, S. Gökden, R. Tülek, J.H. Leach, Q. Fan, J. Xie, Ü. Özgür, H. Morkoç, S.B. Lisesivdin, E. Özbay, New J. Phys. 11 (2009) 063031.

[16] S.B. Lisesivdin, P. Tasli, M. Kasap, M. Ozturk, E. Arslan, S. Ozcelik, E. Ozbay, Thin Solid Films 518 (2010) 5572.

[17] S. Zhang, M.C. Li, Z.H. Feng, B. Liu, J.Y. Yin, L.C. Zhao, Appl. Phys. Lett. 95 (2009) 212101.

[18] S. Zhang, J.Y. Yin, Z.H. Feng, M.C. Li, J.Z. Wanga, L.C. Zhaoa, Superlattice. Microst. 48 (2010) 523.

[19] S.B. Lisesivdin, N. Balkan, E. Ozbay, Microelectron. J. 40 (2009) 413.

[20] S. Birner, S. Hackenbuchner, M. Sabathil, G. Zandler, J.A. Majewski, T. Andlauer, T. Zibold, R. Morschl, A. Trellaki, P. Vogl, Acta Phys. Pol. A 110 (2006) 111.

[21] E. Arslan, M.K. Ozturk, A. Teke, S. Ozcelik, E. Ozbay, J. Phys. D 41 (2008) 155317.

[22] J.H. Davies, The Physics of Low Dimensional Semiconductors, Cambridge University Press, Cambridge, 1998. 364.

[23] S.B. Lisesivdin, A. Yıldız, N. Balkan, M. Kasap, S. Özçelik, E. Ozbay, J. Appl. Phys. 108 (2010) 013712

[24] S. Gokden, R. Baran, N. Balkan, S. Mazzucato, Phys. E. 24 (2004) 249; S. Gokden, A. Ilgaz, N. Balkan, S. Mazzucato, Phys. E. 25 (2004) 86.

[25] S. Çörekçi, D. Usanmaz, Z. Tekeli, M. Çakmak, S. Özçelik, E. Özbay, J. Nanosci. Nanotechnol. 8 (2008) 640.

[26] S.B. Lisesivdin, A. Yildiz, M. Kasap, Opt. Adv. Mater. Rapid Commun. 1 (2007) 467. 